\section{EL DELITO DE LAVADO Y LOS HONORARIOS PROFESIONALES*}

\author{
THE OFFENCE OF MONEY LAUNDERING \\ AND PROFESSIONAL FEES
}
O DELITO DE LAVAGEM DE ATIVOS E OS HONORÁRIOS PROFISSIONAIS

\title{
RESUMEN
}

Los tribunales alemanes llevaron adelante acusaciones contra abogados que defendían a personas acusadas de delitos de tráfico de estupefacientes y en otros casos por estafas, y a raíz de ello imputaron a los defensores el delito de lavado de activos por los honorarios cobrados en el marco de su trabajo de defensa penal.

Es así que el presente trabajo, en forma resumida, intenta demostrar que el cobro de honorarios por parte de los abogados defensores no es ni puede ser tipificado como lavado de dinero, ya que ello afecta distintas garantías constitucionales, tales como el derecho de defensa, el derecho a elegir libremente abogado defensor de confianza, derecho de trabajo, entre otros.

\section{PALABRAS CLAVES}

Lavado de activos obtenidos ilícitamente, derecho constitucional, derecho de defensa, derecho de elegir abogado de confianza, derecho de trabajo, cobro de honorarios, principio de confianza, creación del riesgo.

\footnotetext{
* Artículo de investigación.

a. Abogado, Especialista en Derecho Penal Universidad Austral Argentina, Máster en Investigación Universidad del Rey Juan Carlos España, Prof. Titular Derecho Penal I Universidad Católica de Cuyo San Luis Argentina. Libros: Responsabilidad Penal en la Estructura de la Empresa (edit. BdeF), Delitos de dominio y de infracción de deber (edit. BdeF), Derecho Penal Económico (edit. Nuevo Enfoque), Autoría y participación (edit. BdeF), Derecho Penal Laboral (edit. BdeF).
}

Rafael Berruezo
rafaelberruezo@gmail.com Fecha de recepción: 8 de enero de 2015 Fecha de revisión:: 8 de mayo de 2015 Fecha de aceptación: 09 de mayo de 2015
MISIÓN JURÍDICA

Revista de Derecho y Ciencias Sociales Bogotá, D.C. (Colombia)

Colaboradores Externos Internacionales Núm. 9, Año 2015

Junio - Diciembre, pp. 125 - 141 


\begin{abstract}
The German courts brought forward allegations against lawyers defending people accused of drug trafficking offenses and other fraud cases, and because of that advocates charged the offense of money laundering by the fees charged in connection with his work criminal defense.

Thus, the present work, in summary form, attempts to show that the collection of fees from defense lawyers is not and can be characterized as money laundering, because it affects various constitutional, such as the right of defense guarantees, the right to freely choose trusted lawyer, right to work, among others.
\end{abstract}

\section{KEYWORDS}

Laundering illegally obtained, constitutional law, defense rights, right to choose trusted lawyer, right to work, collecting fees, principle of trust, creating risk.

\section{RESUMO}

Tribunais alemães levaram a julgamento advogados que defenderam pessoas acusadas de crimes de tráfico de estupefacientes e em outros casos por crime de fraude e como resultado os defensores foram imputados do crime de lavagem de dinheiro por taxas cobradas no âmbito do seu trabalho de defesa criminal.

0 presente trabalho tenta mostrar que a cobrança de taxas pelos advogados de defesa não é nem pode ser categorizada como lavagem de dinheiro, uma vez que afeta várias garantias constitucionais, tais como o direito de defesa, o direito de escolher livremente o defensor de confiança, direito ao trabalho, entre outros.

\section{PALAVRAS-CHAVE:}

Branqueamento de capitais obtidos ilegalmente, direito constitucional, direito de defesa, direito de escolher um advogado de confiança, direito do trabalho, cobrança de honorários, criação do risco.

\section{METODOLOGÍA}

La metodología de la investigación consiste en estudiar la problemática expuesta, a partir de los fallos de los tribunales alemanes donde se condenaron a abogados defensores por el delito de lavado de activos de origen ilícito por haber cobrado sus honorarios por su labor defensiva, y desde estos fallos ver, en primer lugar si la conducta de cobro de honorarios puede ser típica a la luz de la doctrina de la imputación objetiva, y luego ver qué derechos constitucionales se afecta con dicha imputación a la luz de la Constitución de la Argentina.

\section{INTRODUCCIÓN}

El presente artículo surge a partir de la noticia de que en Alemania el Tribunal Supremo en el año 2001, dicta una sentencia en la que se iba a condenar a dos abogados por lavado de activos. Estos profesionales ejercían la defensa de un matrimonio contra el que pesaba una acusación por estafa. Para el ejercicio de la defensa los abogados recibieron honorarios, dinero que habría salido del producto de la estafa realizada por el matrimonio. Y a modo de adelante, el Tribunal Supremo Alemán manifestó que el conocimiento de que el dinero cobrado provenía del ilícito encuadra en la figura de lavado de activos.

En cierta forma los fundamentos del Tribunal Supremo, para condenar a los abogados, es lo que se llama "el aislamiento" que se pretende hacer a todo aquel que realice actividades ilícitas como tráfico de drogas, armas, evasión tributaria etc.. Este aislamiento implica que todo aquel que reciba por el motivo que fuere dinero proveniente de actividades ilícitas queda enfrascado en la conducta de lavado de activos. Así dicen los doctrinarios europeos que esto implicaría que, además del abogado podrá ser imputado de lavado de activos por los honorarios que cobre por ejercer la defensa penal, también podrán ser imputados de este delito el médico que atienda al traficante, el dueño del comercio vecino que le vende productos al traficante, el arquitecto que le construye la vivienda, el profesional de ciencias económicas que le lleva los libros, el jardinero, el plomero, y así podríamos seguir enumerando distintas personas que por el hecho de prestar un servicio, conducta neutral, terminarían imputado de lavado de dinero.

A modo de adelanto digamos que, el blanqueo de capitales es el proceso en virtud del cual los bienes de origen delictivo se integran al sistema económico legal con apariencia de haber sido 
obtenidos de forma lícita ${ }^{1}$. Así, esta actividad puede definirse como el procedimiento tendiente a obtener la aplicación en actividades económicas lícitas de una masa patrimonial derivada de cualquier género de conductas ilícitas, con independencia de cuál sea la forma que esa masa adopte, mediante la progresiva concesión a la misma de una apariencia de legalidad ${ }^{2}$.

Si bien es cierto que del estudio de las diferentes posiciones doctrinarias sobre el tema se han extraído dos enfoques predominantes -aquellos que consideran que el blanqueo se basa en la mera ocultación de los bienes de ilícita procedencia y los que mantienen que lo fundamental en el blanqueo es la reintroducción de esos bienes en la economía legal ${ }^{3}$; una adecuada interpretación nos lleva a considerar que estas operaciones no sólo tienden a ocultar o a encubrir el origen ilícito de los bienes o el dinero ${ }^{4}$, sino a hacer aparecer como lícito el producto de operaciones delictivas, enmarcadas bajo actividades comerciales, empresariales y financieras, perfectamente disimuladas como lícitas.

\section{CARACTERÍSTICAS GENERALES DEL LAVADO DE ACTIVOS. CONCEPTO}

Reggiardo Andrés, Presidente de la Comisión Primera del Parlamento Andino, ha expresado que, "se considera blanqueo, el acto de ocultar, encubrir la naturaleza, origen y disposición, movimiento o propiedad del producto, incluyendo el movimiento o conversión del mismo, por transmisión electrónica"s.

También podemos decir que el concepto de lavado de capitales que debe ser utilizado en el Derecho penal es el restringido: el que se refiere exclusivamente al proceso de reconversión de

1. Blanco Cordero, Isidro, El delito de blanqueo de capitales, Pamplona, Aranzadi, 1997, p. 101.

2. Caparros, Fabián, El delito de blanqueo de capitales, Madrid, Colex, 1998, p. 115.

3. Aránguez Sánchez, Carlos, El delito de blanqueo de capitales, Marcial Pons, 2000, p. 32

4. Donna, Edgardo Alberto, Derecho Penal. Parte Especial, 3ra. ed. actual, Santa Fe, Rubinzal-Culzoni, 2007, p. 540.

5. Vilera J. \& Estanga I. El lavado de activos en los países andinos: memorias del taller Ley marco sobfe lavado de dinero o legitimación de capitales, La Paz Bolivia, Santa Fé Bogotá, Colombia, edit. Gente Nueva Editorial, pág. 29. bienes de origen delictivo, quedando fuera de esta noción, al menos en el ámbito del Derecho criminal, la acepción más amplia que incluye a aquellos bienes obtenidos sin el control de la Agencia de Recaudación Estatal. Por lo tanto, como definición con carácter general, decimos que la figura de blanqueo de bienes, es el proceso de ocultación de bienes de origen delictivo con el fin de dotarlos de una apariencia final de legitimidad $^{6}$.

En síntesis, el blanqueo o reciclaje de dinero proveniente de la comisión de delitos se ha convertido en un tema central de la política criminal dirigida contra la criminalidad organizada. Por eso se impone un esfuerzo mancomunado tendiente a poner fin a esta desdeñable práctica ${ }^{7}$.

\section{ACTUACIÓN DEL ABOGADO}

Una de las motivaciones que ha guiado a legisladores para punir a los abogados por lavado de activos por el cobro de honorarios o por asesoramiento, lo podemos encontrar en lo siguiente; uno de los instrumentos jurídicos en la lucha contra las organizaciones criminales de todo tipo, y en especial contra las que dominan el tráfico de drogas u otros delitos a través de los cuales se obtienen grandes beneficios económicos, es el delito de blanqueo de capitales, en la medida en que tiende a impedir la satisfacción del móvil económico que mueve su realización. De este modo la conexión políticocriminal entre el delito de blanqueo de capitales y la lucha contra la delincuencia organizada hace que los déficits de persecución y sanción

6. Trovato Gustavo Fabián, Articulo 303, Código Penal y normas complementarias 12 Artículos 300/316, edit. Hammurabi, 2012, pág. 568. Ver también Martínez-Bujan Pérez Carlos, Derecho penal económico, Tirant lo Blanch, 2002, pág. 319.

7. "El delito de lavado de activos y la garantía constitucional del ne bis in ídem". Reflexiones sobre el fallo de la Sala I de la Cámara Federal de Casación Penal en "Jiménez, Jancy s/ recurso de casación" por Carlos Gonella -Fiscal General subrogante de la PGN, a cargo de la Procuraduría de Criminalidad Económica y Lavado de Activos. Ex Fiscal General ante los Tribunales Orales de Córdoba (2009/2012), especialista en Derecho Penal por la Universidad Nacional de Córdoba y docente de Derecho Penal por concurso de la Universidad Nacional de La Rioja (2007/2010)- y Diego Luciani -Secretario de Fiscalía General ante la Cámara Federal de Apelaciones de San Martín. Ex fiscal federal de Mercedes, especialista en Derecho penal y docente de Derecho penal en la Universidad Nacional de Buenos Aires-. 
penal directa de las organizaciones criminales se intenten compensar mediante una regulación especialmente laxa del delito de blanqueo de capitales, llevando a la práctica la filosofía que permitió condenar en la jurisdicción penal a Al Cappone: si no podemos juzgar y sancionar los delitos principales cuya comisión es la fuente directa de generación de los beneficios económicos ilícitos, castiguemos al menos como delictivas las conductas derivadas que se conecten con el disfrute de los capitales ilícitamente obtenidos. De esta manera se aislar al autor y se le hace patente que no puede conseguir el objetivo perseguido, esto es, el disfrute de lo alcanzado con el delito ${ }^{8}$.

Es decir, como ya se referenció, es la aplicación de la política del aislamiento del delincuente, en pocas palabras la política del "Derecho penal del enemigo", pensamiento tan atacado en doctrina, pero que es clara su aplicación por parte de los legisladores en esta temática.-

Para una mejor comprensión del tema podemos dividir la actuación del abogado en dos etapas, una, previa a la comisión del delito de lavado de activos y una segunda, posterior a la comisión del delito, donde el abogado es contratado a los fines de ejercer la defensa penal de quien está siendo imputado del ilícito de lavado de activos.

\section{I. Actuación anterior a la comisión del delito de lavado de activos}

Para el análisis de esta primer etapa, que podría llegar a ser la más conflictiva, porque estamos hablando de la asesoramiento impositivo, constitución de empresas etc., que llevarían a permitir darle al dinero ilícito apariencia de lícito, seguiremos el análisis efectuado por Sánchez-Vera Gómez-Trelles, quien efectúa un análisis desde los institutos de la imputación objetiva.

Así tenemos que en las denominadas "operaciones" contra el blanqueo de capitales, cada vez es más habitual, empero, la imputación de letrados en ejercicio, como pretendidos colaboradores en los supuestos delitos de

8. Pérez Manzano Mercedes, Neutralidad delictiva y blanqueo de capitales: el ejercicio de la abogacía y la tipicidad del delito de blanqueo de capitales, La Ley Penal, № 53, octubre 2008, edit. La Ley, pág. 1. blanqueo de capitales cometidos por terceros, a quienes habrían asesorado ilícitamente. En particular a abogados que prestar asesoramiento en materia mercantil y fiscal ${ }^{9}$.

En esta etapa se trata de la cuestión de cuándo el asesoramiento legal, puede ser considerado un favorecimiento del delito de lavado de activos, o cuándo esto puede ser aprovechado por un tercero $\mathrm{y}$ en consecuencia acarrear responsabilidad penal para el letrado. Y en este sentido, hay una regulación cada vez más expansiva, en donde si el abogado conoce que una determinada estructura societaria por él creada puede ser utilizada por su cliente para el blanqueo de capitales, debe responder, y a este conocimiento del letrado se llega en forma indiciaria; el cliente que no va a blanquear capitales -se deduceno necesita de complejas estructuras societarias, por lo tanto el abogado que creó tales personas jurídicas o el abogado que asesoró sobre determinados modos fiscales, también conocía la finalidad última de las mismas, esto es, el blanqueo de capitales ${ }^{10}$.

Ahora bien parte de la doctrina, estos casos de asesoramiento previo al lavado de activos, lo analizan desde la imputación objetiva y así determinar si esta conducta de asesoramiento es típica o no.

a. Creación del riesgo: Desde el análisis de la creación del riesgo, tenemos que el asesoramiento del abogado en la medida que se haga en cumplimiento de normativas sobre el actuar del letrado, esta actuación cae bajo el riesgo permitido, aún cuando pueda dar, aprovechada por terceros, a un delito de blanqueo de capitales; $y$, toda actuación letrada que no respete tales postulados, se halla fuera del riesgo permitido, lo cual, no conlleva ya de forma directa responsabilidad: se habrá cumplido la primer premisa de la fórmula de la imputación objetiva, esto es la creación del riesgo, pero habrá que comprobar si tal riesgo se ha concretado en el resultado ${ }^{11}$.

9. Sánchez-Vera Gómez-Trelles Javier, Blanqueo de capitales y abogacía, InDret 1/2008, pág. 4

10. Ibídem, pág. 5. En este sentido, el STS de 30 de marzo de 2007 , en la que se señala que el Tribunal a quo había tomado como indicios la supuesta existencia de "operaciones extrañas a las prácticas comerciales ordinarias", así como "de un entramado societario... que supone acudir a ese medio para gestionar dos gasolineras", criterio este último que fue descartado por el Tribunal Supremo en la sentencia indicada.

11. Ibídem, pág. 11. 
Las recomendaciones del GAFI, impone a los abogados el deber de reportar operaciones sospechosa, obligación de dudosa constitucionalidad. Pero lo cierto es, siguiendo a Sánchez-Vera, que la práctica diaria demuestra que el nivel de exigencia a ciertos profesionales, como a los abogados, se halla fuera de la realidad de las cosas: exigir a particulares que lleven a cabo verdaderas actividades de policiales ajenas totalmente a su profesión, constituye la atribución de una suerte de rol social que en realidad no les corresponde. Esto sucede, específicamente, en aquellos casos en los cuales los supuestos límites, por existir la incriminación del delito de blanqueo en su modalidad imprudente, la pretendida infracción del deber de cuidado por parte del letrado puede acabar siendo deducida, por el incumplimiento de tales, exacerbados, deberes ${ }^{12}$.

Es por ello, nos dice Sánchez-Vera, que no puede dejar de sorprender, una vez iniciada una investigación judicial por blanqueo de capitales, que se pretenda que personas que supuestamente se dedican de forma pública y notoria al delito, no hubiesen sido perseguidas policialmente, $y$, empero se desplacen dichos deberes de vigilancia policial retroactivamente hacia un abogado, atribuyéndole ex post unos deberes de control como si fuesen ellos los profesionales encargados de tal persecución. Esto es importante, ya que también tiene repercusión a nivel del tipo subjetivo, porque esta expansiva técnica legislativa y judicial acaba atribuyendo el dolo al abogado o a otros particulares un conocimiento, sobre actividades ilícitas de sus clientes, que curiosamente, la propia Policía no tenía, a pesar de ser ellos los técnicos en criminalística; por lo que habrá que concluir que el tan público y notorio presunto blanqueo no debía ser (procedencia ilícita del dinero), con el lógico y consecuente corolario de tener que exonerar a los profesionales ${ }^{13}$.

b. Principio de confianza: Cuando pensamos y analizamos el comportamiento del letrado desde este principio, tenemos que el abogado debe poder acogerse plenamente al principio de confianza con respecto a sus clientes, aún cuando, fácticamente, se sabe que habrá clientes que puedan defraudar dicha confianza. Este principio de confianza

\section{Ibídem, pág. 15}

13. Ibídem, pág. 15. Ver STS 5 de octubre de 2006 (abogado y director de una sucursal bancaria), Fundamentos jurídicos 5 y 6 . impone un deber de cautela en el deber general de comunicación que ha sido impuesto al abogado, de modo tal que la actual normativa de blanqueo no debe ser interpretada en el sentido de un deber de comunicación inmediato, sin más. Pensemos que tales deberes antiblanqueo deben conjugarse con las propias obligaciones del letrado que existen ex lege, es decir que, si bien tiene esta obligación de reportar operaciones sospechosas, también esta comunicación de datos a terceros extraños a la relación de confianza letrado/cliente, puede vulnerar el secreto profesional y el derecho a la intimidad del cliente.

Por otro lado, tenemos que el principio de confianza se muestra como un importante límite frente a criterios meramente causales de atribución en coautoría o de extensión de responsabilidad de la mano de la figura de la accesoriedad. Por ejemplo; se abre un procedimiento penal por el delito de blanqueo, y se imputa no sólo al supuesto o supuestos blanqueadores, sino también a diversos empleados de bancos, a notarios y abogados. Sin embargo, esta suerte de imputación global o conjunta, todos como coautores o como cooperadores necesarios (accesoriedad), debe ser tomada una vez más con suma reserva; por ejemplo, un abogado constituye diversas sociedades con capital extranjero, para la ejecución de una operación inmobiliaria, podrá ampararse en que tal dinero ya ha pasado el "filtro" bancario en cuanto a la prevención de blanqueo, es decir, podrá ampararse en el principio de confianza, igual que el Registro de la Propiedad que finalmente inscribe el cambio de titularidad del bien inmueble en su registro, pudiendo ampararse en que todos los intervinientes anteriores en la operación se han comportado conforme a Derecho, por lo tanto, se ampara en el principio de confianza ${ }^{14}$.

Además, esto llevo a que el abogado que se ampara en el principio de confianza, sea necesario la comprobación del dolo, que en estos casos es sumamente difícil. Esto así, ya que un abogado que discute si su comportamiento queda amparado por el principio de confianza respecto de su cliente, a la vista del banco de donde procede el dinero de su cliente, y además dicho alegato exonerante, es prima facie, válido; y

14. Ibídem, pág. 20. 
también podrá ejercer su defensa argumentando que obro en error de tipo sobre el origen ilícito de los fondos, en donde la clase de error tenderá a ser inevitable ${ }^{15}$. Por lo tanto el dolo del abogado ha de inferirse de los elementos del tipo objetivo, es decir, de la base fáctico-normativa acaecida. Por lo tanto la imputación al letrado de una serie de conocimientos, entre ellos muy particularmente sobre el origen ilícito de los fondos lavados, resultará en muchas ocasiones poco fundada ${ }^{16}$.

c. Prohibición de regreso, actos neutrales: Según este instituto, la línea de imputación queda interrumpida sin retroceder a "riesgo" (condiciones) anteriores cuando existe ya un riesgo completo que se ha dirigido libre y consciente a la producción del resultado, es decir, que puede afirmase que se ha concretado el resultado ${ }^{17}$.

En la actualidad dentro de la teoría de la prohibición de regreso, se estudia lo que se ha denominado en doctrina "los actos neutrales", esto implica afirmar que, un comportamiento cotidiano no es punible como participación aunque suponga una contribución fáctica a la realización de un determinado delito, cuando puede mantenerse que dicho comportamiento queda plenamente cubierto por el rol social lícito en el que se interactúa, es decir, que supone un simple acto neutral ínsito en dicho $\mathrm{rol}^{18}$. Así el analista penal no entrará a valorar si quien así se comporta tuvo "conocimiento" de estar interviniendo instrumentalizado en un ilícito ajeno, o si dicho "conocimiento" no se tuvo pero debería haberse adquirido porque en estos casos, una vez más, sucede que no existe tipicidad objetiva por falta de riesgo jurídicamente desaprobado, de modo tal que ni tan siquiera es necesario analizar una pretendida tipicidad subjetiva del comportamiento ${ }^{19}$.

El Tribunal Supremo español, en su sentencia 34/2007, de 1 de febrero, expresa:

15. Ibídem, pág. 22.

16. Ibídem, pág. 23

17. Ibídem, pág. 25.

18. Ibídem, pág. 26.

19. Ver, Robles Planas Ricardo, Las conductas neutrales en el ámbito de los delitos fraudulento, pág. 51 y ss.
La doctrina reciente estima que estos actos (los denominados neutrales) son comportamientos cotidianos socialmente adecuados, que por regla general no son típicos. Tal es el caso del que aparece como adquirente de un inmueble en un contrato de compraventa. Lo que plantea esta cuestión es la exigencia de que toda acción típica represente, con independencia de su resultado, un peligro socialmente inadecuado. Desde este punto de partida, una acción que no representa peligro alguno de realización del tipo carece de relevancia penal. El fundamento de esta tesis es la protección del ámbito general de libertad que garantiza la Constitución... A estos fines la teoría y algunas jurisprudencias europeas han elaborado diversos criterios para establecer las condiciones objetivas en las que un acto 'neutral' puede constituir una acción de participación. En este sentido se atribuye relevancia penal, que justifica la punibilidad de la cooperación, a toda realización de una acción que favorezca el hecho principal en el que el autor exteriorice un fin delictivo manifiesto, o que revele una relación de sentido delictivo, o que supere los límites del papel social profesional de cooperante, de tal forma que ya no puedan ser consideradas como profesionalmente adecuadas, o que se adapte al plan delictivo del autor, o que implique un aumento del riesgo.

Es así entonces que, ante un 'acto neutral' hay ausencia de imputación objetiva, pues, el comportamiento no representa peligro alguno de que se vea concretado en el resultado. Así la actividad negocial de la vida cotidiana, ejemplo prestación de servicios o la venta de mercancías usuales, no dan lugar obviamente al delito de blanqueo de capitales. El dueño de un hotel que aloja en su establecimiento a alguien de quien se sospecha pueda ser narcotraficante, no lleva a cabo delito alguno, a pesar de que con el pago de la factura por hospedaje el presunto delincuente está introduciendo ganancias ilícitas en el mercado lícito. Y ello, porque el sujeto no estará sino comportándose dentro de su rol de hotelero, y tampoco existen, especiales deberes de información al respecto; no hay un 'fin delictivo manifiesto', no se revela con el cobre de la factura 'una relación de sentido delictivo', ni se superan 'los límites del papel social profesional del cooperante', ni el empresario 'se adapta al plan delictivo del autor' o su comportamiento 'implica un aumento del riesgo $0^{20}$.

20. Sánchez-Vera Gómez- Op cit. pág. 29. 
Respecto a la neutralidad de las conductas en derecho penal, Pérez Manzano ${ }^{21}$, nos dice que, no existen conductas per se neutrales, pues cualquier conducta que genéricamente y en abstracto pueda calificarse de neutral, eso es, de penalmente irrelevante y atípica, puede adquirir sentido delictivo y ser, por tanto, penalmente relevante si se dan ciertas condiciones entre las cuales es esencial la inserción de dicha conducta en un contexto delictivo, por ello no puede excluirse con carácter general la tipicidad de clases de acciones ni tampoco la actividad estándar que en abstracto pueda considerarse inherente al ejercicio de la profesión. Es por ello que hay que analizar el comportamiento desde la imputación objetiva, y así determinar la imputación del comportamiento. Para esto es importante partir de que el dolo o el mero conocimiento no determina la relevancia penal de la conducta, aun cuando los conocimientos especiales del autor deban tenerse en cuenta en la determinación de la tipicidad de la concreta conducta analizada. Por otro lado, la conexión de la acción inicialmente neutral con la realización de un delito por otro es requisito necesario pero no suficiente para afirmar la tipicidad de la conducta, es presupuesto de la tipicidad, pero no el elemento que decide la relevancia penal de la conducta, sólo la concurrencia de especiales circunstancias que permitan concluir la existencia de forma clara y unívoca de una especial relación de sentido delictivo entre la conducta inicialmente neutral y el delito puede modificar el carácter neutral de la conducta y convertirla en típica.

Con los argumentos de los actos neutrales podemos afirmar y adelantándonos, que el cobro de honorarios por parte de un letrado, nunca puede dar lugar al delito de blanqueo de capitales, igual que la empresa de suministro de energía eléctrica, o de agua, o el dueño del supermercado, veterinario por la atención de mascotas del traficante, médico que atiende una enfermedad del mismo, no deberán responder por tal delito aún cuando el dinero recibido sea de procedencia ilícita. Porque todos estos comportamientos son puros 'actos neutrales' que no dan lugar a imputación, en modo alguno podría concluirse que se trata de conductas que sólo tienen el sentido de apoyar la conducta delictiva del blanqueador, son antes bien, meros actos de cobro de lo debido ${ }^{22}$.

21. Pérez Manzano Mercedes Op. cit., pág. 3.

22. Sánchez-Vera Gómez-Op. cit., pág. 31.
En definitiva, afirma Pérez Manzano ${ }^{23}$ que, la conducta del cobro de honorarios no está incorporada a la legislación española sobre la prevención del blanqueo de capitales y en consecuencia nada dice sobre la forma en la que debe producirse el cobro de honorarios por la actividad realizada, sea la asesoría o la defensa de los clientes acusados de la comisión de delitos a través de los cuales se hayan podido generar beneficios ilícitos. Por tanto, el caso debe examinarse de acuerdo con los criterios generales; esto es, deberá analizarse si puede hablarse de una especial relación de sentido delictivo entre el cobro de honorarios y el delito previo por existir colusión o de deberes de garante. Por consiguiente, como en la mayoría de los casos no existirán deberes de garante -de impedir el delito-, sólo en caso de colusión podrá entenderse que puede haber responsabilidad por blanqueo de capitales. A la misma conclusión llegamos por la vía de la interpretación material restrictiva realizada del tipo de blanqueo de capitales, pues esta interpretación encaja en la exigencia general de colusión entre quien realiza una conducta aparentemente neutral y quien ha obtenido beneficios del primer delito para desvincular los beneficios de su origen ilícito y de esta forma proceder a la consolidación de la capacidad económica conseguida.

\section{d. Consideraciones acerca del bien jurídico}

Por otro lado, se analiza apelando a reflexiones de carácter teleológico-normativas. Por consiguiente, la conducta del abogado como una prestación de servicios usuales socialmente o estándar, no afectan el fin de protección de la norma, porque la aceptación de honorarios no representa la entrada de los bienes en la circulación económica legal. No obstante, el intento de concretar o restringir el tipo penal a través de consideraciones normativas destaca el problema más importante: no existe un criterio único acerca de cuál es el bien jurídico protegido, cuestión que constituye el punto de partida de una interpretación teleológico-normativa en el ámbito jurídico penal ${ }^{24}$.

\section{Pérez Manzano Mercedes Op. cit, pág. 23.}

24. Wirtz Georg Bermejo Mateo G., Honorarios de los abogados defensores en causas penales y blanqueo de capitales desde una perspectiva europea: ¿un mismo problema, una misma solución? Zeitschrift für Internationale Strafrechtsdogmatik (disponible online en http://www.zis-online.com/), Nro. 11/2007, pág. 454. 


\section{e. Actuación de acuerdo al rol}

El punto esencial de la argumentación de Müssig ${ }^{25}$ es la adecuación al rol de un acuerdo de honorarios en el contexto normativo de la defensa penal. La aceptación, de una defensa penal, por parte del abogado, en razón de que el defendido ha cometido un hecho punible catalogado en el § 261 StGB como uno de los delitos previos del blanqueo de capitales, no debe afectar el carácter adecuado al rol de un acuerdo de honorarios y de su recepción. El defensor penal sólo actúa fuera de los límites de su rol cuando actúa con dolo directo: "Según principios generales, la regla de presunción de adecuación al rol no sólo se pone en cuestión cuando la conducta se adapta al contexto delictivo, sino, también, cuando la conducta, en razón de su forma adecuada socialmente (estereotipada) lleva en sí misma 'de forma general el estigma de un contexto delictivo' [...] Como un criterio objetivo puede considerarse también el conocimiento claro, por parte del abogado defensor, del origen delictivo de los honorarios". La propuesta de Müssig es una aplicación en la teoría del delito de la interpretación conforme a la Constitución, que se analiza más abajo, y que fue utilizada por el Tribunal Constitucional alemán para resolver este caso.

\subsection{Actuación del abogado posterior a la comisión del ilicito}

Por otro lado tenemos la actuación del abogado posterior a la comisión del ilícito de lavado de activos cuando la persona imputada del delito designa un abogado de su confianza y cobra honorarios por dicha tarea. El cobro de honorarios por ejercer la defensa ha sido cuestionada y ha sido encuadrada en la conducta de lavado de activos, por un tribunal alemán, como fue explicado brevemente en la introducción al presente trabajo.

En relación al tema, tenemos que el fallo del Tribunal Estadual Superior de Hamburg (06.01.2000, NJW 2000, 673) que se trata del siguiente hecho: un abogado, el que luego fue acusado, aceptó la defensa de una traficante de drogas que se encontraba detenida. Como anticipo de honorarios recibió 5.000 marcos alemanes.

La Fiscalía formuló acusación contra el abogado por lado de activos. Si bien el tribunal tuvo por probado que el dinero provenía de delitos vinculados con el tráfico de estupefacientes. En

25. Ibídem, pág. 454. la causa no se pudo determinar si el abogado tenía conocimiento de esta circunstancia o bien si, lo sabía no le importo el origen del dinero. El Tribunal Estadual Superior de Hamburgo opinó que no era necesario continuar investigando el hecho pues no podría condenarse al abogado inclusive cuando se pudiera establecer que tenía conocimiento seguro del origen del dinero. $\mathrm{Y}$ de esta forma el Tribunal consideró que el abogado no sería punible por lavado de dinero aun cuando se demostrara que este tenía conocimiento del origen del dinero.

Algunos argumentos esgrimidos por el Tribunal Superior de Hamburgo (OLG), fueron que, en el caso se plantea una evidente colisión entre, por un lado, la voluntad de aislar económicamente a los delincuentes que explica la sanción de lavado de activos y, por otro lado los derechos fundamentales, por un lado los de todos procesado a la libre elección de un letrado que lo defienda y por otro al de los abogados al libre ejercicio de la profesión. Además el Tribunal hace una observación en relación a la discusión legislativa en la oportunidad de la tramitación del § 261 del Código Penal alemán, sobre la duda que plantea de si la pretensión de aislar económicamente a los delincuentes debía llevarse hasta el extremo de criminalizar las conductas de atención de las necesidades más cotidianas, como la alimentación, vestimenta, el consumo de servicios médicos, de abogados etc.

Además expresa el tribunal que la subsunción en el § 261 del Código Penal el pago de honorarios restringe el derecho a la elección de abogado y afecta el libre desarrollo de la profesión, pero además afecta a la confianza entre cliente y abogado, y abre la posibilidad de que el abogado designado renuncie a la designación al conocer importantes detalles de los casos ante la posibilidad de ser procesado por lavado de activos, o a ser sujeto de investigación con medidas tales como, allanamientos, intervenciones telefónicas etc. En definitiva si se aceptara esto, se provocaría un notable debilitamiento de la posición procesal de la defensa penal.

También se expresa en el fallo, que el castigo del abogado que cobre sus honorarios con dinero que provienen del ilícito previo en nada contribuye al sustento de la criminalidad que se pretende combatir, sino que, el acto de retribuir económicamente a la defensa supone más una 
carga para el imputado que un incentivo que pueda moverle a cometer el delito: normalmente se cometen delitos lucrativos porque el autor quiere obtener algún tipo de rendimiento con las ganancias de su conducta, no para verse implicado en un proceso penal y poder pagar un abogado. Por lo tanto, dice el tribunal, el cobro de honorarios por parte de los abogados defensores en un proceso penal no puede quedar objetivamente abarcado por el tipo de lavado de dinero ${ }^{26}$.

En el año 2001, el tiempo al Tribunal Superior Federal llega una causa similar, siendo esta que los abogados acusados defendían a un matrimonio al cual se le atribuía haber cometido estafas por sumas millonarias. Cado uno de los abogados recibió, en efectivo, la suma de 200.000 marcos alemanes como adelantos en concepto de honorarios más el derecho a que les sea entregada a ellos la caución constituida para suspender la ejecución del auto de prisión preventiva, por un monto de 500.000 marcos. El Tribunal Regional de $1^{\circ}$ instancia condenó a los abogados como autores de lavado de dinero en razón del cobro del dinero en efectivo y los absolvió en lo referente a la adquisición del derecho a reclamar la entrega de la caución.

El Tribunal Superior Federal confirmó la condena pero revocó la absolución sobre la base de que creía correcto, también en ese punto, aplicar una condena conforme el § 261 StGB. La sentencia dedica muy poca atención a los argumentos de la doctrina y a los fundamentos del Tribunal Estadual Superior.

26. A esta afirmación el Tribunal plantea tres excepciones en donde un abogado defensor puede ser imputado por el delito de lavado de activos, a saber: a) los casos en que los bienes adquiridos provienen de la previa comisión de un delito cuya víctima está perfectamente identificada, por ejemplo, en el supuesto que a un abogado se le paga sus honorarios obtenidos del pago de un rescate por el secuestro de una persona, o con el botín del robo a una entidad bancaria. En estos supuestos la conducta del letrado si debe ser objetivamente constitutiva de delito, pues contribuye de forma directa al empobrecimiento de la víctima y se perjudican intereses constitucionalmente reconocidos, como el derecho a la propiedad; b) otra excepción, es cuando la actuación del abogado interfiere en el normal funcionamiento de la administración de justicia, lo que sucede cuando el letrado no se limita a asistir procesalmente a su cliente, sino que interviene en el hecho objeto del procedimiento pretendiendo alterarlo de forma favorable a su defendido y participa en la transmisión de los bienes procedentes del delito previo; c) y por último, los casos en que el pago de honorarios no es más que un fraude a la prohibición de lavado de activos, por ejemplo, cuando el abogado actúa como fiduciario del blanqueador.
El Tribunal Supremo, entendía que el cobro de honorarios a sabiendas de su origen delictivo tiene perfecta cabida en el § 261 del Código Penal, sin que del tenor gramatical de este precepto pueda deducirse una excepción para el caso de los defensores penales o sus retribuciones, una posibilidad que en la tramitación legislativa fue expresamente rechazada por el legislador. Además deja en claro que la condena de este tipo de conductas no implica una intromisión ilegítima en el derecho al libre ejercicio de la profesión de abogado o en la libre elección de defensor, ya que estos derechos no incluyen la posibilidad de retribuir o ser retribuido con dinero de origen ilícito. Y en el supuesto de que los acusados no tuvieren la posibilidad de pagar los honorarios de su abogado con dinero que no tuviera origen ilícito, su derecho de defensa está garantizado con el defensor de oficio.

Además aclara que con la interpretación que se le hace al caso, no se afecta la relación de confianza entre el cliente y el abogado, ya que las posibles injerencias que surjan de la incoación de diligencias penales contra el abogado deben basarse en unos indicios de criminalidad que han de ir más allá del mero hecho de que el imputado cuente con un abogado de libre designación.

Contra esta sentencia del BGH y contra dos sentencias del Tribunal Regional de Frankfurt fueron interpuestos recursos constitucionales. La Sala Segunda del Tribunal Constitucional Federal, bajo la presidencia de Hassemer, decidió todos ellos de modo unificado y se llegó, en lo relativo al derecho penal material, a la siguiente conclusión:

“El parágrafo 261, inc. 2, $n^{\circ} 1$ del Código Penal es compatible con la ley fundamental, siempre y cuando los defensores penales sean amenazados con penas únicamente cuando hubieran tenido al momento de la recepción de los honorarios conocimiento seguro de su procedencia"

Además expresan que, más allá de la libertad de trabajo, se deduce del Estado de Derecho el derecho de defensa del imputado a una defensa penal efectiva en un proceso justo, que le garantice "hacerse defender en el proceso penal por un abogado de su elección y su confianza art. 6 parr. 3.c Convención Europea de Derechos Humanos". Suplir la designación de un abogado defensor por una defensa de oficio se excluye por dos razones: por un lado, no se puede 
imponer ilimitadamente que los abogados defensores "resuelvan una situación de riesgo creada por el legislador penal renunciando a su cargo de defensor elegido, para ser designado defensor de oficio". Y en segundo lugar, antes de que se dicte una sentencia condenatoria firme, un imputado "que presuntamente sólo dispone de dinero sucio, no debería ser tratado sin más de igual modo que aquél que carece de medios"27.

En el fallo comentado, el Tribunal Constitucional alemán consigue restringir la aplicación del tipo penal de acuerdo con una interpretación conforme a la Constitución, por medio de una ponderación de los principios de la libertad de trabajo y del fair trial con la "importante causa comunitaria" de la prevención del blanqueo de capitales, al que el Estado Federal Alemán se ha obligado internacionalmente a través de los Convenios ya mencionados. El principio de proporcionalidad no ordena una exención completa para el defensor penal de la amenaza de pena del § 256 apartado 2 Nro. 1 del Código Penal alemán. Pero el ejercicio de la libertad de trabajo del abogado defensor penal y la institución de la elección del defensor permiten sólo la imposición de pena ${ }^{28}$

Cuando el defensor penal sepa con seguridad en el momento de la recepción de los honorarios (o de un anticipo de los mismos) que éstos provienen de la comisión de un delito. La transmisión de bienes de origen delictivo bajo el amparo de la relación de confianza protegida constitucionalmente es un abuso de la posición privilegiada del defensor, que no merece ninguna protección constitucional. Si el defensor penal conoce, al momento de recibir los honorarios, con seguridad, que los bienes obtenidos provienen de un hecho delictivo, el abogado se coloca, entonces, fuera de su rol de órgano de la Administración de Justicia"29 .

Esta afirmación el Tribunal la funda recurriendo a la delimitación entre el dolo directo y el dolo eventual en que el "significado de la defensa penal

27. Tribunal Constitucional alemán del 30 de marzo de 2004.

28. Wirtz Georg Bermejo Mateo G., Honorarios de los abogados defensores en causas penales y blanqueo de capitales desde una perspectiva europea: ¿un mismo problema, una misma solución? Zeitschrift für Internationale Strafrechtsdogmatik (disponible online en http://www.zis-online.com/), Nro.11/2007, pág. 456.

29. Tribunal Constitucional alemán del 30 de marzo de 2004. para un proceso penal justo y conforme al Estado de Derecho y la responsabilidad que le corresponde al abogado defensor en salvaguarda de esta misión" prohíben que el abogado defensor "abuse de su posición hasta el punto de una actuación conjunta con su cliente y de evadir a sabiendas el mandato de la Ley.

Una posible solución podría consistir en aplicar al ámbito de la colaboración postdelictiva aquellos planteamientos defendidos por Jakobs, que considera que un comportamiento que de modo estereotipado es inocuo no constituye participación en una organización no permitida, incluso en aquellos casos en que quien realiza dicha conducta conoce las intenciones del sujeto con el que interacciona ${ }^{31}$.

Así vemos que en Alemania parte de la doctrina y jurisprudencia, mantienen la opinión de que los abogados penalistas como cualquier otro partícipe de la vida económica es autor posible del delito de blanqueo de capitales. Pero otro sector entiende que dados los peligros que ello comporta para el libre ejercicio de la abogacía y para la efectividad de la defensa, debe efectuarse una limitación de la aplicación del tipo en estos casos ponderando los fines que el delito pretende cumplir y los derechos en conflicto. Dicha limitación tendrá sus efectos, para unos, en el marco del tipo objetivo, entendiendo que la conducta es social o profesionalmente adecuada. En tanto que para otros la restricción se efectuaría en el ámbito del tipo subjetivo. Y una tercera postura, afirman que debe aplicarse una causa de justificación específica para los abogados construida a partir de la especial posición constitucional del defensor penal y la presunción de inocencia del inculpado ${ }^{32}$.

Pérez Manzano ${ }^{33}$, adhiere a la postura de que la cuestión debe resolverse en la tipicidad

\section{Tribunal Constitucional alemán del 30 de marzo de 2004.}

31. Jakobs Gunther, La imputación objetiva en Derecho penal, Madrid, 1996, pág. 106/107.

32. Cfr., Pérez Manzano Mercedes, Neutralidad delictiva y blanqueo de capitales: el ejercicio de la abogacía y la tipicidad del delito de blanqueo de capitales, La Ley Penal, $N^{o}$ 53, octubre 2008, edit. La Ley, pág. 12

33. Pérez Manzano Mercedes, Neutralidad delictiva y blanqueo de capitales: el ejercicio de la abogacía y la tipicidad del delito de blanqueo de capitales, La Ley Penal, № 53, octubre 2008, edit. La Ley, pág. 12. 
objetiva, de modo que el cobro de honorarios por los abogados es conducta neutral y atípica, salvo que por razones excepcionales dicho cobro pueda ser interpretado como ocultación de los bienes del delincuente, esto es, como forma de desvinculación de los bienes de su origen ilícito. Así podría ser el cobro de honorarios mucho más alta de lo habitual puede que sea para ocultar bienes del delincuente, de la misma manera que a través de una factura sobre otro bien o servicio.

Al igual que en el supuesto anterior, aquí se echa mano a la doctrina de los actos neutrales, y en este sentido Choclán Montalvo ${ }^{34}$, nos dice que:

La neutralidad de la acción es un criterio todavía insuficiente, porque es claro que determinados actos neutrales pueden resultar típicos cuando se insertan en un contexto delictivo. De este modo, las restricciones al tipo deberán obtenerse por razones relativas al fin de protección de la norma penal del blanqueo de capitales. Si atendiéramos sólo al tenor literal del tipo sería inequívoca la relevancia típica del pago del servicio profesional del Abogado en los casos en que conoce el origen delictivo del dinero, pues, en ese caso, el Abogado adquiere un bien de origen ilícito, y el imputado lo habrá transformado en un bien lícito, adquiriendo en su lugar servicios de un Abogado, evaluables económicamente... podemos sostener con cierta seguridad que el cobro de honorarios del cliente por parte del Abogado que lo defiende en el proceso penal y que no sabe con seguridad que el dinero procede de un delito, no realiza objetivamente el tipo penal del blanqueo de capitales; por el contrario, sí lo realiza la acción del Abogado que factura honorarios en los casos de simulación o de participación voluntaria en el plan del autor erigiéndose en fiduciario del cliente como un eslabón más de la cadena de lavado de dinero. En los demás casos, determinar cuándo el percibo de honorarios es un mero acto neutral, profesionalmente adecuado, y cuándo deja de serlo para adquirir sentido delictivo dependerá de las circunstancias de cada caso. También de lo que entendamos por acto neutral y si para determinar lo que es valorativamente neutro deben tomarse en consideración o no los

34. Choclán Montalvo José Antonio, Blanqueo de capitales y retribución del abogado. El pago de honorarios con cargo al patrimonio presuntamente criminal. La Ley Penal, № 53 , octubre 2008, edit. La Ley, pág. 3. conocimientos especiales de quien lo realiza. Y, en todo caso, de la determinación del alcance de la norma penal en función de su fin de protección. Cuestiones todas ellas sobre las que no puede profundizarse más en estas breves reflexiones.

Para Wirtz y Bermejo ${ }^{35}$, el tipo de blanqueo de capitales debería ser restringido al dolo directo, pues la ilimitada aplicación de formas dolosas e imprudentes del tipo penal lesiona el derecho de defensa del imputado. Tanto en Alemania como en España se encuentran vigentes tipos penales de blanqueo de capitales de amplia redacción, cuyo tenor incluye la aceptación de honorarios por parte de los abogados defensores en procesos penales. En ambos países existen opiniones críticas que reclaman una delimitación del sentido literal de los tipos penales.

Las formas tradicionales de argumentación no alcanzan para delimitar el sentido literal de los tipos penales en cuestión. El Tribunal Constitucional alemán ha constatado que el tipo penal de blanqueo de capitales no podía ser delimitado a través de una interpretación literal, sistemática, histórica o teleológica. Por ello, argumenta en pos de una solución por la vía constitucional, en la cual los intereses en juego se ponderan unos contra otros. Además, el derecho de defensa tiene un peso tan importante que permite fundar una excepción a la regla de la punibilidad por blanqueo de capitales. Con esta fundamentación, la excepción obtiene una legitimación que los otros criterios de interpretación no pueden proveer.

Con fundamento en el derecho internacional, la solución del Tribunal Constitucional alemán también es posible en España. Si bien el Tribunal Constitucional español no se encuentra vinculado por la resolución de su homónimo alemán, sí puede decirse que las sentencias del Tribunal Constitucional alemán y del Tribunal Europeo de Derechos Humanos tienen una fuerte influencia sobre la jurisprudencia española.

35. Wirtz Georg Bermejo Mateo G., Honorarios de los abogados defensores en causas penales y blanqueo de capitales desde una perspectiva europea: ¿un mismo problema, una misma solución? Zeitschrift für Internationale Strafrechtsdogmatik (disponible online en http://www.zis-online.com/), Nro. 11/2007, pág. 457 


\section{RESPETO DE LAS GARANTÍAS CONSTITUCIONALES}

Debemos decir que, los derechos fundamentales, como el derecho de defensa, son defensas que tienen los individuos frente a las intervenciones del Estado. De ello se deduce que el ejercicio de un derecho fundamental no requiere justificación alguna; lo que requiere justificación es la limitación de un derecho fundamental. En contra partida los derecho fundamentales nunca pueden ser invocados por las autoridades públicas en contra de un individuo, por ejemplo, el Ministerio Fiscal no puede invocar derechos fundamentales que lo amparen contra el procesado. No existe en este sentido ninguna teoría que autorice una desnaturalización semejante ${ }^{36}$.

Debemos decir que el abogado desarrolla la función constitucional de defensa, y constituye obligación de los poderes públicos, también de Jueces y Tribunales, el garantizar al justiciable que pueda defender sus pretensiones de modo real y efectivo, permitirle la defensa y asistencia de Abogado en los términos establecidos en la Constitución y las leyes. El Abogado participa de la función pública de la Administración de Justicia, mediante el ejercicio libre de la profesión con las limitaciones que las establecidas en la Constitución y las leyes, y por las normas éticas y deontológicas. Pero sucede que, con frecuencia, en el actual modelo de proceso agresivo, de expansión del poder de intervención del Estado y correlativo sacrificio de la libertad del individuo, que se está progresivamente implantando en nuestra práctica forense cuando se trata de la investigación de determinados ilícitos, entre los que ocupa papel destacado el delito de blanqueo de capitales, y en el que se aprecia una importante involución en el sistema de garantías de los inculpados. Imaginemos la siguiente situación, el Juez de Instrucción, desde el primer momento, embarga e interviene con carácter cautelar la totalidad del patrimonio del imputado (todo, y a veces también el de sus familiares más próximos), privándole de la posibilidad de atender las más elementales necesidades cotidianas, y desde luego, de disponer de cantidad alguna para el pago de honorarios, a pesar de que la Constitución garantiza el derecho a designar libremente el abogado y de que la defensa sea preceptiva. Debemos adelantar

36. Bacigalupo Enrique, Principios constitucionales de derecho penal, edit. Hammurabi, 1999, pág. 27. que la legislación argentina prevé el decomiso aún sin sentencia previa. Entonces es alarmante comprobar cómo el Juez de Instrucción podría, en estos casos, permanece indiferente ante esta situación, presumiendo, contra reo, que si ha elegido libremente a un abogado es porque dispone de rentas ocultas con las que satisfacer sus honorarios (en una ocasión un Juez resolvió no pagar el colegio de los hijos del imputado porque había elegido un abogado de prestigio y presumía el Juez que el imputado disponía de rentas ocultas -es un caso real-). De este modo se impone al cliente la carga de buscar bienes no sujetos a la intervención judicial, y al Abogado el cobro de sus honorarios de terceros o con bienes ocultos, o, con mucha frecuencia, sencillamente no cobrar $^{37}$.

Aclaro ello y considerando, que está de más decir que es extremadamente importante efectivizar y reforzar los controles que se llevan adelante para contrarrestar este tipo delictivo; no es posible dejar de mencionar que en este aspecto se ha llegado a puntos que tornan inconstitucional algunos aspectos de la norma, y que en el caso que nos ocupa nos es otro que el derecho de defensa que tiene todo imputado y que se vería por demás cercenado, si se considera que los pagos que recibe el abogado en concepto de honorarios permiten cometer el delito que se está examinando, y que de este modo también se estaría lavando dinero y, por ende, el abogado también estaría actuando fuera de lo que marca la ley.

Un Juez que adopta una medida cautelar de carácter patrimonial no debe restringir el ámbito del riesgo permitido socialmente hasta el punto de no permitir riesgo alguno a costa de sacrificar en caso de duda el derecho a la asistencia letrada. Ese celo en la tutela de la sociedad, del aseguramiento del proceso, puede representar una medida cautelar desproporcionada. Debemos tener siempre presente que la presunción de inocencia, no sólo es un derecho relativo a la carga de la prueba, una regla de juicio conforme a la cual únicamente es posible dictar una condena tras un plenario contradictorio y con base en prueba inequívoca de cargo, sino que también es una actitud de los Tribunales para con el imputado, una regla que impone un tratamiento como

37. Choclán Montalvo José Antonio, Blanqueo de capitales y retribución del abogado. El pago de honorarios con cargo al patrimonio presuntamente criminal. La Ley Penal, $N$ o 53, octubre 2008, edit. La Ley, pág. 4. 
inocente, mientras no sea declarado culpable, de modo que sus derechos fundamentales únicamente admiten restricciones cuando el fin sea constitucionalmente legítimo y en todo caso con criterios estrictos de proporcionalidad ${ }^{38}$.

\section{DERECHO DE DEFENSA}

Los tratados internacionales firmado por Argentina ${ }^{39}$, consagran en forma pormenorizada y detallada todos los derechos y garantías que tiene el individuo sometido a proceso penal, viniendo así a completarse no sólo entre ellos mismos sino también con los originarios de los artículos 18 y 19 de nuestra Constitución Nacional, configurando una constelación de normas supremas dentro de nuestro ordenamiento jurídico ${ }^{40}$.

En Argentina las declaraciones, derechos y garantías se confieren al individuo en tanto persona, sea ciudadano o extranjero. En cuanto a la observancia por el Estado, tales derechos deben ser respetados y tutelados al individuo tanto por el Estado federal como por los provinciales. De modo que las instituciones y los poderes de cada uno de ellos deben hacer estricta aplicación de los mismos, no pudiendo ser alterados, distorsionados, limitados o violados

38. Choclán Montalvo José Antonio, Blanqueo de capitales y retribución del abogado. El pago de honorarios con cargo al patrimonio presuntamente criminal. La Ley Penal, $N^{o}$ 53, octubre 2008, edit. La Ley, pág. 5. En este sentido, por ejemplo, en los Estados Unidos, la Sección 1957 del US Code considera impunes «las transacciones necesarias para preservar el derecho de defensa técnica garantizado por la Sexta enmienda de la Constitución».

39. Declaración Americana de los Derechos y Deberes del Hombre de 1948; la Declaración Universal de Derechos Humanos de 1948; la Convención Americana sobre Derechos Humanos de 1969; el Pacto de Internacional de Derechos Civiles y Políticos y su Protocolo facultativo de 1966; y la Convención contra la Tortura y otros Tratos o Penas Crueles, Inhumanos o Degradantes de 1984.

40. Jauchen Eduardo M. Tratado de Derecho Procesal Penal, T. I, edit. Rubinzal Culzoni, 2012, pág. 83. Es bueno aclarar que: Las declaraciones son normas escritas que formulan enunciados supremos, estableciendo pautas, ideologías o principios rectores sobre cuestiones determinadas. Los derechos son las prerrogativas y facultades otorgadas al individuo, adjudicándole atribuciones derivadas de los principios del valor justicia. Los derechos son otorgados al hombre en reconocimiento y protección de su propia condición humana. Las garantías son las instituciones o instrumentaciones que precisamente tiene como fin la tutela y aseguramiento para que el individuo pueda gozar y ejercer efectivamente los derechos que se le confieren. Los derechos puede ser ejercidos erga omnes, esto es, frente a los demás individuos y frente al Estado. En cambio, las garantías sólo pueden ser invocadas frente al Estado. Pág. 84. por las legislaciones inferiores, incluidas las constituciones provinciales ${ }^{41}$.

La abogacía es una noble profesión universitaria de fuerte sentido académico, profundo contenido social e indisolublemente comprometida con la democracia constitucional. Es, además, una profesión lícita, legítima, sometida a estatuto, reglamentada, que en muchos campos requiere especialización para su óptimo desempeño. Y por tanto, toda persona tiene derecho a ser bien defendida y a elegir libremente quien lo haga. No debe coartarse la libre elección del defensor, así como el abogado dispone del derecho a la defensa en su más cabal y estricto sentido socio-jurídico, pues es su lícita profesión y vocación por la tutela del Derecho.

Para toda persona imputada de un delito y por el cual se la somete a proceso, el derecho de defensa es el derecho por excelencia, el supremo e inviolable, el que, más allá de su contenido genérico, implica múltiples derivaciones. Así Seco Villalba dice, "La defensa, antes que derecho positivo, es una fuerza que tiene su origen en la oscura guarida del instinto de conservación ${ }^{42 " .}$

El derecho de defensa en el derecho positivo argentino, está consagrado en la Constitución Nacional, la que expresamente dispone en su artículo 18 que "Es inviolable la defensa en juicio de la persona y de los derechos." Además está en los artículos 9 y 11 de la Declaración Universal de Derechos Humanos; artículo 8 de la Convención Americana sobre Derechos Humanos, artículo 14 del Pacto Internacional de Derechos Civiles y Políticos, y art. 26 de la Declaración Americana de los Derechos y Deberes del Hombre. Normas todas que son parte de la Constitución Nacional en virtud a lo dispuesto por el artículo 75, inc. 22.

Si bien, la garantía del derecho de defensa, es aplicable a toda clase de proceso, civil, comercial, laboral etc., tiene su especial relevancia en el proceso penal como consecuencia de la supremacía de los

\section{Ibídem, pág. 85.}

42. Seco Villalba, cita de Jauchen Eduardo. Op. cit., pág. 109. 
bienes en él comprometidos. En este último podemos definirlo, expresa Jauchen43, como "el insoslayable derecho subjetivo individual, de carácter público, de intervenir en el proceso penal en todo momento, de probar y argumentar en él, por sí y por medio de abogado todas las circunstancias de hecho y fundamentos de Derecho que desvirtúen la acusación, con el propósito de obtener una declaración de eximición o atenuación de la responsabilidad penal atribuida."

En un sentido amplio, el derecho de defensa, se liga con el principio del debido proceso y todos los que son sus consecuencias, y en sentido restringido, es la concreta oposición a la acción penal frente a la jurisdicción. Así, el derecho de defensa no sólo es aplicable a cualquier proceso, sino también que, en el proceso penal, pertenece al imputado $\mathrm{y}$ a las otras partes privadas que eventualmente intervengan en el mismo: querellante pro delito de acción pública o privada, actor civil, tercero civilmente demandado y citado en garantía ${ }^{44}$.

Explicado ello, podemos decir que una solución aceptable de la problemática de la defensa penal en casos de lavado de dinero no puede buscarse sólo en el campo del Derecho Penal material. Ella debe ser acompañada con disposiciones coadyuvantes del Derecho Procesal Penal. En la discusión alemana esto ha sido estudiado bajo los llamados "delitos post-cedentes", donde una participación posterior al hecho presupone la existencia de un hecho antecedente. La problemática ha recibido un tratamiento procesal especial en los casos de exclusión del defensor por la sospecha de que participó en el hecho punible que se investiga en el procedimiento. La solución en el caso del lavado de dinero, no debería apartarse de los límites legalmente establecidos.

Digamos también que, el derecho de defensa implica con respecto al imputado su facultad de intervenir en el proceso, en todas sus etapas y actos procesales, desde el más prematuro inicio, esto es, cuando por cualquier medio se anoticie de que ha sido sindicado como responsable de un delito o al ser detenido y hasta su total

43. Ibídem, pág. 110.

44. Ibídem, pág. 111. terminación, o sea, cuando haya cesado el cumplimiento de la penal o medida de seguridad. La importancia de su intervención está dada, por el derecho que este tiene de controlar el desarrollo regular del procedimiento, de ofrecer pruebas, de controlar la producción de las pruebas de cargo, de ser oído expresando en su descargo todas las explicaciones pertinentes que considere necesarias, de alegar personalmente o por medio de su abogado, o ambos, efectuándose todas las fundamentaciones críticas de hecho y de Derecho contra los argumentos acusatorios y sobre el valor de las pruebas ${ }^{45}$.

Podemos decir que, si bien puede dudarse que el derecho a la libre elección de Abogado o el ejercicio libre de la profesión comprenda el derecho al cobro con bienes que se sabe proceden de un delito, no hay razón para excluir la prevalencia de estos derechos cuando no se sabe seguro cuál es la procedencia del dinero. No sería asumible el sacrificio de los derechos fundamentales a la libre elección de Abogado, a la defensa, y al ejercicio libre de la Abogacía, disuadiendo a los abogados de aceptar la defensa del cliente, cuando no hay certeza de que los honorarios se satisfacen con dinero ilícito. A falta de conocimientos especiales, cuando el cobro de honorarios se sitúa en los estándares normales en su cuantía y forma de realizar la transacción económica, cuando se ha realizado un examen cuidadoso de la situación por parte del abogado, no hay motivo para que el abogado renuncie a asumir la defensa y el pago de sus honorarios. En estos casos es tolerado el riesgo de realización del tipo, no constituye un riesgo jurídicamente desaprobado el cobro de los honorarios, pues debe favorecerse la asunción de la defensa, ante la duda (in dubio pro defensa), como actividad necesaria para el adecuado funcionamiento del proceso penal y para garantizar el derecho a la defensa técnica del imputado ${ }^{46}$.

Además de estar afectando el derecho de defensa con estas sentencias, también se está afectado otras garantías que tiene toda persona, esto es, estado de inocencia, juicio previo, que tienen su basamento constitucional. Por lo tanto,

45. Ibídem, pág. 112.

46. Choclán Montalvo. Op cit., pág. 2. 
nadie puede ser condenado como culpable de un delito si no es por sentencia fundada en pruebas legalmente introducida al juicio y que tengan la eficacia acreditante suficiente para demostrar con certeza aquel extremo, de modo que toda pena sólo puede ser impuesta previo juicio en el cual, como debido proceso legal, se hayan respetado los pasos y principios enunciados que pueden resumirse en las etapas de acusación, defensa, prueba y sentencia. Así las cosas, el imputado lego, sin perjuicio de sus aptitudes y conocimientos que en casos aislados puedan tener, necesita de un jurista que lo asesore sobre sus derechos, lo asista y represente a fin de controlar que se respete la legalidad del debido proceso previamente establecido por la Constitución y la ley, que técnicamente refute las pruebas y argumentos de cargo y ponga el énfasis en las pruebas y argumentos de descargo, tanto de hecho como de Derecho ${ }^{47}$.

En consecuencia, la defensa técnica es necesaria y obligatoria, aún en contra de la voluntad del imputado. La misma implica que el imputado puede elegir como defensor particular a cualquier abogado de "su confianza" . La necesidad y obligatoriedad está reflejada en los distintos códigos procesales, al establecer que, si el imputado no designa un abogado de su confianza por los motivos que fueran, el Estado le provee el Defensor Oficial. Es decir que en ningún momento la persona imputada puede estar sin un abogado defensor que lo asista en el proceso penal.

Expresa Binder ${ }^{49}$ que, "Según nuestro régimen constitucional, el defensor es un asistente directo del imputado; en tal carácter, debe guiarse por los intereses y necesidades de su cliente. No cumple una función pública, sino que asesora a una persona en particular. Su misión y su actuación, conforme a las reglas éticas, deben ceñirse a defender los intereses del imputado. En la medida en que lo haga, el defensor estará contribuyendo a que ese proceso responda a las exigencias del Estado de Derecho, y en esto último consiste su función pública o social."

47. Jauchen Eduardo M. Op cit., pág. 115.

48. Jauchen Eduardo M. Tratado de Derecho Procesal Penal, T. I, edit. Rubinzal Culzoni, 2012, pág. 116.

49. Binder Alberto M., citado por Jauchen Eduardo M. Tratado de Derecho Procesal Penal, T. I, edit. Rubinzal Culzoni, 2012, pág. 119.

\section{LIBRE ELECCIÓN DE ABOGADO}

Como lo venimos diciendo, la consecuencia necesaria de la exigencia de una defensa técnica es el derecho a contar con un abogado defensor, único profesional capacitado y autorizado para llevar adelante esta elevada misión. Así, la Convención Americana sobre Derechos Humanos dispone en su artículo 8 inc. 2, letra d, el derecho "del inculpado de defenderse personalmente o de ser asistido por un defensor de su elección y de comunicarse libre y privadamente con su defensor"; en la letra e, se establece el derecho "irrenunciable de ser asistido por un defensor proporcionado por el Estado, remunerado o no según la legislación interna, si el inculpado no se defendiere por sí mismo ni nombrare defensor dentro del plazo establecido por la ley". En tanto el Pacto Internacional de Derechos Civiles y Políticos dispone en su artículo 14 inc. 3, letra b, que durante el proceso, toda persona acusada de una delito tiene derecho "A disponer del tiempo y de los medios adecuados para la preparación de su defensa y a comunicarse con un defensor de su elección"; y en la letra d, reafirma el derecho "A hallarse presente en el proceso y a defenderse personalmente o ser asistida por un defensor de su elección; a ser informada, si no tuviere defensor, del derecho que le asiste a tenerlo y, siempre que el interés de la justicia lo exija, a que se le nombre defensor de oficio, gratuitamente, si careciere de medios suficientes para pagarlo"50.

\section{CONCLUSIÓN}

Nunca antes de la aparición del lavado de activos como figura autónoma del delito de encubrimiento o favorecimiento real se había cuestionado el origen de los fondos con los que los abogados cobraban los honorarios por su defensa en juicio. Lo que resulta altamente llamativo que actualmente, se haya instalado esta opinión de que el abogado que cobra honorarios provenientes de un delito como pago de la defensa en juicio comete el delito de blanqueo cuando la única actividad de su cliente queda atrapada en alguno de los delitos subyacentes ${ }^{51}$.

\section{Jauchen Eduardo M. Op cit., pág. 139.}

51. Adriasola Gabriel, Lavado de activos en Uruguay. Los riesgos de una autonomía desmedida. En, Política criminal y dogmática penal de los delitos de blanqueo de capitales. V.A., edit. Idemsa Lima Perú, pág. 33. 
Se trata de una peligrosa aplicación de los tipos de blanqueo que se ha realizado en Europa extendiéndola a la recepción de honorarios "maculados" por parte de los abogados. Esta extensión del tipo del blanqueo a los honorarios recibidos no ya por un asesoramiento sino por la defensa en juicio, pretende cercar al delincuente, de modo que no pueda acceder a una defensa de su elección poniendo en riesgo al abogado sobre quien debería recaer la carga de indagar el origen lícito o ilícito de los fondos con que se pagan sus honorarios. De este modo, si la persona acusada sólo tiene como fuente de ingresos una actividad criminal, se desvanece su derecho a la libre elección de un defensor. Bajo estas reglas, "un abogado penalista debe preguntar primero a un patrocinado con mucho efectivo, si ese dinero lo ha conseguido legalmente o si lo declararía bajo juramento". Este aislamiento legal al delito organizado se acerca claramente al concepto de derecho penal del enemigo, negándole incluso un derecho esencial del Estado democrático de derecho cual es la libre elección del defensor, limitando ésta elección a la defensa de oficio ${ }^{52}$.

Se ha tratado de limitar esta aplicación del tipo penal del blanqueo recurriendo a una interpretación restrictiva del tipo objetivo. De ese modo, se excluyen de la punibilidad la recepción de honorarios sin una tendencia interna de beneficiar al autor del delito o de dañar a la víctima ${ }^{53}$.

Otro intento de limitación ha sido en el tipo subjetivo, condicionando así, la justificación del abogado defensor a su buena fe en el momento de aceptación de sus honorarios. A juicio de Adriasola, debe preferirse una solución de justificación objetiva basada en el interés preponderante. En efecto, se dan acá dos intereses, por un lado e de las autoridades de perseguir y aislar al crimen organizado, y por el otro, el de preservar la integridad del derecho a la defensa en juicio. Este último interés debe preponderar sobre el primero aún a riesgo de soportar la impunidad de los abogados de mala fe, pues de lo contrario implicaría un tratamiento diferencial a determinados autores de delito, ya no como ciudadanos, sino como enemigo. En definitiva, así como se pretende mediante la figura del lavado

52. Ibídem, pág. 33.

53. Ibídem, pág. 34. de dinero cercar económicamente al delincuente, también esta tesis pretende cercarlo en el ejercicio de su derecho de defensa, coartándole uno de los más elementales derechos del debido proceso, la libre elección del abogado. Se sostiene que en esos casos puede recurrir a la abogacía de oficio. No obstante, ello violenta igualmente la libre elección pues restringe el ámbito de profesionales al que puede acceder la persona sometida a juicio ${ }^{54}$.

En definitiva podemos afirmar que es una exageración la doctrina referida a los "honorario maculados", que ha llevado a algunos fiscales a sostener que los narcotraficantes no tiene derecho a utilizar abogados de particular confianza, con el argumento de que los dineros de que proceden aquellos, están contaminados, por lo que solo sería lícita la defensa de oficio provista por el Estado ${ }^{55}$, ya que de esta forma se afectan distintas garantías constitucionales, y se está aplicado ni más ni menos que la doctrina del derecho penal del enemigo que tan cuestionada ha sido por los doctrinarios.

\section{Ibídem, pág. 35}

55. Langón Cuñarro Miguel, Lavado de dinero y política criminal en el Uruguay, En, Política criminal y dogmática penal de los delitos de blanqueo de capitales. V.A., edit. Idemsa Lima Perú, pág. 249. 


\section{BIBLIOGRAFÍA}

- ADRIASOLA, Gabriel. Lavado de activos en Uruguay. Los riesgos de una autonomía desmedida. En, Política criminal y dogmática penal de los delitos de blanqueo de capitales. V.A., edit. Idemsa Lima Perú, 2012.

- ARÁNGUEZ, Carlos. El delito de blanqueo de capitales. Marcial Pons, 2000.

- BLANCO, Isidro. El delito de blanqueo de capitales. Pamplona, Aranzadi, 1997.

- BACIGAlUPO, Enrique. Principios constitucionales de derecho penal. edit. Hammurabi, 1999.

- CAPARROS, Fabián. El delito de blanqueo de capitales. Madrid, Colex, 1998.

- CHOCLÁN, José. Blanqueo de capitales y retribución del abogado. El pago de honorarios con cargo al patrimonio presuntamente criminal. La Ley Penal, № 53, octubre 2008

- DONNA, Edgardo. Derecho Penal. Parte Especial, 3ra. ed. actual, Santa Fe, RubinzalCulzoni, 2007.

- GUNTHER, Jakobs. La imputación objetiva en Derecho penal. Madrid, 1996, pág. 106/107.

- JAUCHEN, Eduardo. Tratado de Derecho Procesal Penal, T. I. edit. Rubinzal Culzoni, 2012.
- PÉREZ, Mercedes. Neutralidad delictiva y blanqueo de capitales: el ejercicio de la abogacía y la tipicidad del delito de blanqueo de capitales. La Ley Penal, № 53, octubre 2008.

- ROBLES, R. Las conductas neutrales en el ámbito de los delitos fraudulento, Revista brasileira de ciências criminais, ISSN 14155400, №. 70, 2008, págs. 190-228.

- SÁNCHEZ-VERA, GÓMEZ-TRELLES, J. Blanqueo de capitales y abogacía. InDret 1 , 2008.

- TROVATO, Fabián. Articulo 303, Código Penal y normas complementarias 12 Artículos 300/316. edit. Hammurabi, 2012.

- VILERA J. y ESTANGA, I. El lavado de activos en los países andinos: memorias del taller Ley marco sobfe lavado de dinero o legitimación de capitales. La Paz Bolivia, Santa Fé Bogotá, Colombia, Edit. Gente Nueva Editorial,1994.

- WIRTZ, Mateo. Honorarios de los abogados defensores en causas penales y blanqueo de capitales desde una perspectiva europea: ¿un mismo problema, una misma solución?. Zeitschrift für Internationale Strafrechtsdogmatik (disponible online en http://www.zis-online.com/), Nro. $11 / 2007$. 
